\title{
Designing aesthetics for play(fulness)
}

\author{
Jesper Falck Legaard ${ }^{1}$ \\ ${ }^{1}$ Designskolen Kolding \\ $j f l @ d s k d . d k$
}

\begin{abstract}
Product design is developed and communicated through aesthetics (e.g. form, color, personality), enabling a link between design intention and resulting experience. More precisely, designers develop both functional affordances and the meaning that the product is intended to convey, in order to mediate certain experiences. Whilst aesthetics in a general sense has often been a subject for research, there is less research on how aesthetics more specifically relates to play and playfulness in experiences.

In this paper I explore the connection between the aesthetics of a product and play(ful) experiences, focusing on the research question; "What is the link between aesthetic affordances and play experiences?"

In the paper I describe the identification of six basic play forms and the development of aesthetic principles relating to the play forms, extracted through a study with design students from Design School Kolding. I exemplify how the principles can relate to different product categories, both in relation to toys and to objects that are not intended for playing, but can be considered 'playful'.

My take on play experiences builds on the 'Play Blueprint' by Legaard (2018) describing four main activities within play, these being Construction, Storytelling, Investigation and Bodily activity. Grouping these categories two and two led to six distinct forms of play, which all relate to particular drivers of play activities also described in the Play Blueprint, these being autonomy, chance, pleasure and imagination.

The contribution of the paper is the classification of the six play forms and establishing a link between the play forms and aesthetic principles, aiding designers in designing objects for particular play/playful experiences.

The intention is to aid designers to incorporate design aesthetics that adds playfulness and 'joy' (Overbeeke et al, 2003) leading to more engaging product designs, or to design products eliciting meaningful play experiences, possibly directed at specific learning outcomes by nudging the user towards specific types of play/playful behaviors.
\end{abstract}

Keywords: Play, playfulness, aesthetics, engaging design 


\section{Introduction}

The design tradition has seen many approaches to aesthetics through trending styles, but also trending aesthetic principles such as 'form follows function' (Sullivan, 1896) or the opposite 'form follows fun' (e.g. Peter, 2013) have been influential. The latter - form follows fun - is much more recent, but is an interesting counterpoint to the functional perspective. It is a counterpart where form and function are not related, i.e. where form is related to imagination and storytelling instead of the function. Norman and Verganti (2013) describe what they term 'design-driven innovation' in a similar manner, using the well-known Alessi "Form Follows Fiction" product line by Stefano Giovannoni as an example where it can be seen that new designs and new contexts may lead to radical innovations in terms of the meaning they bring about. This product line of personified kitchen tools completely changed the way people perceived kitchenware and the meaning that people associated with kitchenware.

When Pine and Gilmore in 1998 introduced the term experience economy, it brought an increased focus on how companies can offer experiences as (part of) their offering, in line with the experiences that consumers would need or desire. That also brought a focus on how to design products with explicit focus on the experiential content/value of products, described by e.g. Hassenzahl (2010) as experience design, og by e.g. Jensen \& Coxon (2013) as experience-based designing, the latter emphasizing that the design is for/based on experiences (rather than a design of experiences) and the procedural approach of the design perspective. Overbeeke et al. (2003) ask of designers to make things more engaging, and for design that goes beyond ease of use towards enjoyment of the experience, writing that "A user may choose to work with a product despite it being difficult to use, because it is challenging, seductive, playful, surprising, memorable or rewarding, resulting in enjoyment of the experience." (ibid: 11)

Folkmann (2013) describes the non-functional aspects of the product design as a surplus of meaning in line with Bailey and Story (2018) who also address the two diverse sides of a design. They (ibid: 246) write that "design objects are difficult to assess according to this aesthetic approach because unlike art, they are also concerned with questions of function; design 'objects' (as in, the productions of design) must address practical human needs if they are to be deemed useful. Thus, the aesthetic quality of design objects is as much about capacity to fulfil a particular need as it is about appearance to the eye. Perceptions of usefulness cannot be separated from appearance, as these qualities form part of the sensuous character of a designed object."

Approaches to balance these two sides of product design typically relate to affordances (combining functionality and understanding of use) and semantics as the expression or 'surplus of meaning'. Blythe and Hassenzahl (2003: 99) describe what they note as 'semantics of fun', writing that „During fun the senses must be engaged, there must be spectacle. The bright and luminous colours of children's toys, the gaudy kitsch sets of the popular game show, the explosions of light and sound in popular film are instances of the spectacle of fun. Attention is "grabbed", we demand increasingly violent distraction; the leisure society is also the society of the spectacle. Spectacle and wild colour signal and signify fun. Subdued pastels do not. If there is an aesthetic of fun then it is gaudy, and fleeting, it bursts at the eye like a firework."

They focus on the intensity of perceptual stimulation as the main point in designing for ,fun'. However, as described in the following, there are many play(ful) activities that do not require intense perceptual stimulation, so whilst this might be relevant for some experiences in relation to fun/play, it does not provide a broadly applicable approach. Other researchers, e.g. Kudrowitz and Wallace (2010) work from specific classifications of play, hereby incorporating play forms and the connection to the experience of play more broadly, although 
their classifications (like most other) of e.g. constructive play, still has the drawback that a construction activity in itself is not necessarily play. Such classifications need refinement in order to be more accurate of a play experience. The aim of this paper is to add such refinement, starting from a similar approach by defining a group of play forms, but also explicating how the play forms can be seen as pairs of play activities which, when coupled, enhance the playfulness towards a specific play form. Furthermore, I derive specific motivational drivers linked to the specified play forms, and introduce a scale describing the correlation between aesthetic principles and specific play forms. This scale, in combination with the identification of the main drivers of the different play forms, is the main contribution of this study, and can be useful for both analyzing existing artifacts and designing new artifacts that elicit play(ful) experiences.

\section{Method}

The study described in this paper was developed in two stages:

First an exploration of theoretical approaches to designing for play experiences combined with the development of a new classification of play activities/types, and the relation between them. This initial stage of the project was done in order to establish a relevant foundation for the further research into the relation between play experiences and aesthetics. Many of the current classifications of play types have been critiqued (see e.g. Kudrowitz and Wallace, 2010; Legaard 2018) for either being too broad (e.g. 'object play') or based on singular activities (e.g. 'constructive play') that are not very useful for play designers, since they either encompass all experiences, or they are not necessarily playful, when viewed only as singular activities.

The exploration in regards to play types took a starting point in the four activities defined by Legaard (2018) in the Play Blueprint, and led to the development of six play forms as described in section 3. These were used as the foundation for the second part of the study. The second part - an empirical study with design students - was done with the intention of developing new knowledge about the correlation between aesthetic expression and specific play forms. The study was done as part of a course in the 'Design for Play' master's programme at Design School Kolding, entitled 'Designing for play experiences'. It was done as part of this course partly because of the obvious relevance to the course theme, but also because the group of design students doing the course had a previous understanding of both aesthetics and play, which was deemed important to get the most valuable outcome of the study. There were approximately thirty students participating in the empirical study, which is described in section 4.

\section{Identifying six play forms and their motivational drivers}

Play is essentially a mode of being, relating to the meta-reality of the play experience. We consider play to be 'bracketed' (Gordon, 2009) in its own experiential space, meaning that it forms a metareality that you immerse yourself in when you play. Beside the immersed experience of play, it can also be experienced as instances in non-play experience, providing a sense of playfulness. Sicart (2014: 21) writes about playfulness that "We need play, but not all of it-just what attracts us, what makes us create and perform and engage, without the encapsulated singularity of play."

The differentiation between the two is typically just that; play objects (e.g. toys) relate to their own bracketed play space in which people immerse during the experience, whereas playfulness can be elicited through other types of products (e.g. tools) in non-play 
experiences, in order to achieve a sensation of play, but without the immersion into the play experience.

When Blythe and Hassenzahl (2005) equate fun with distraction, the point is also that the 'fun' part of the experience is something that is not directed at a purpose/outcome of the experience. Play (and the instances of playfulness) is also described by Jensen (2014) as something that is non-goal oriented, meaning that it allows us to be in a state that is open and explorative. This state is typically imbued with positive emotions (see e.g. Webster et. al., 1993).

Play and playfulness can come from any object, i.e. anything can be (considered) a toy. We can rapidly switch between free play (for instance playing around with a ball) and playing within a structured game-framing (turning the play with the ball into a match) or using an object for a functional purpose. As Verbeek (2011: 15) describes it: "human-world relationships should not be seen as relations between preexisting subjects who perceive and act upon a preexisting world of objects, but rather as sites where both the objectivity of the world and the subjectivity of those experiencing it and existing in it are constituted." While play experiences are characterized by the immersion in the experience, they also contain frequent disruptions from the immersion, e.g. when those playing together stop the activity for a second to agree on who has the ninja and who has the princess.

Oppositely a non-play experience can have instances of play, which adds to the playful sensation of the experience, as illustrated below.

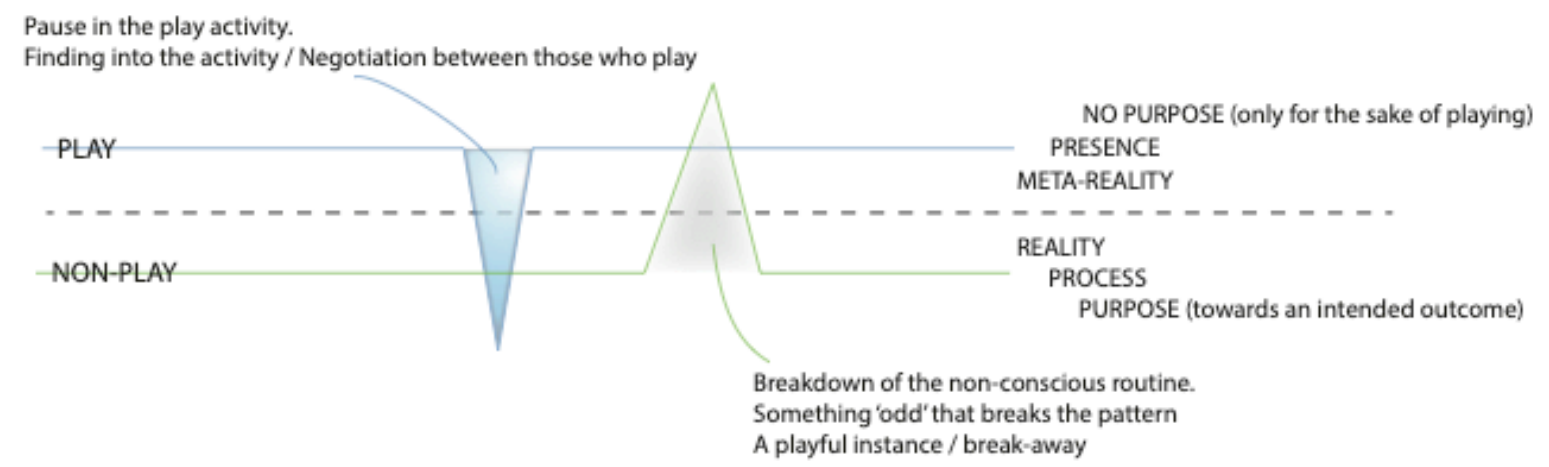

Figure 1. The figure depicts the difference and relation between the two modes, in which the expression of the object plays an important part in e.g. triggering playful instances.

Figure 1 was developed by juxtaposing existing research on play experiences (e.g. De Valk et al, 2015; Legaard, 2018) and research of immersion in experiences (e.g. Csíkszentmihályi , 1990; Ladwein, 2003; Caru and Cova, 2006). It illustrates how instant shifts of an experience typically occur, either as brief breakdowns of a play activity where 'reality' is in focus, or playful breakaways from procedural experiences, where something that is odd or surprising suddenly switch the attention and mode of being for an instant. You typically return right back to the mode of being that is dominant for you in that moment. So, the play activity is an engagement with an object (and perhaps other players) where the usage (communicated through affordances) and expression (surplus of meaning) comes together to allow certain forms of play to emerge.

As mentioned earlier, it is interesting that none of the activities in, for instance, the 'Play blueprint' by Legaard (2018), would be play by themselves. This led to exploring how pairing the activities in groups of two might create new ways to classify play experiences, which indicated that the activities become play experiences through their connection to another activity, e.g. when construction is combined with storytelling. The exploration led to six distinct play forms, believed to be descriptive of more substantial play forms, rather than just 
singular activity types. The outcome of this exploration is illustrated in figure 2 below, depicting a set of six basic play forms and their origins:

- Embodied investigation (EI)

- Constructive investigation (CI)

- Investigative storytelling (IS)

- Constructive storytelling (CS)

- Embodied storytelling (ES)

- Embodied construction (EC)

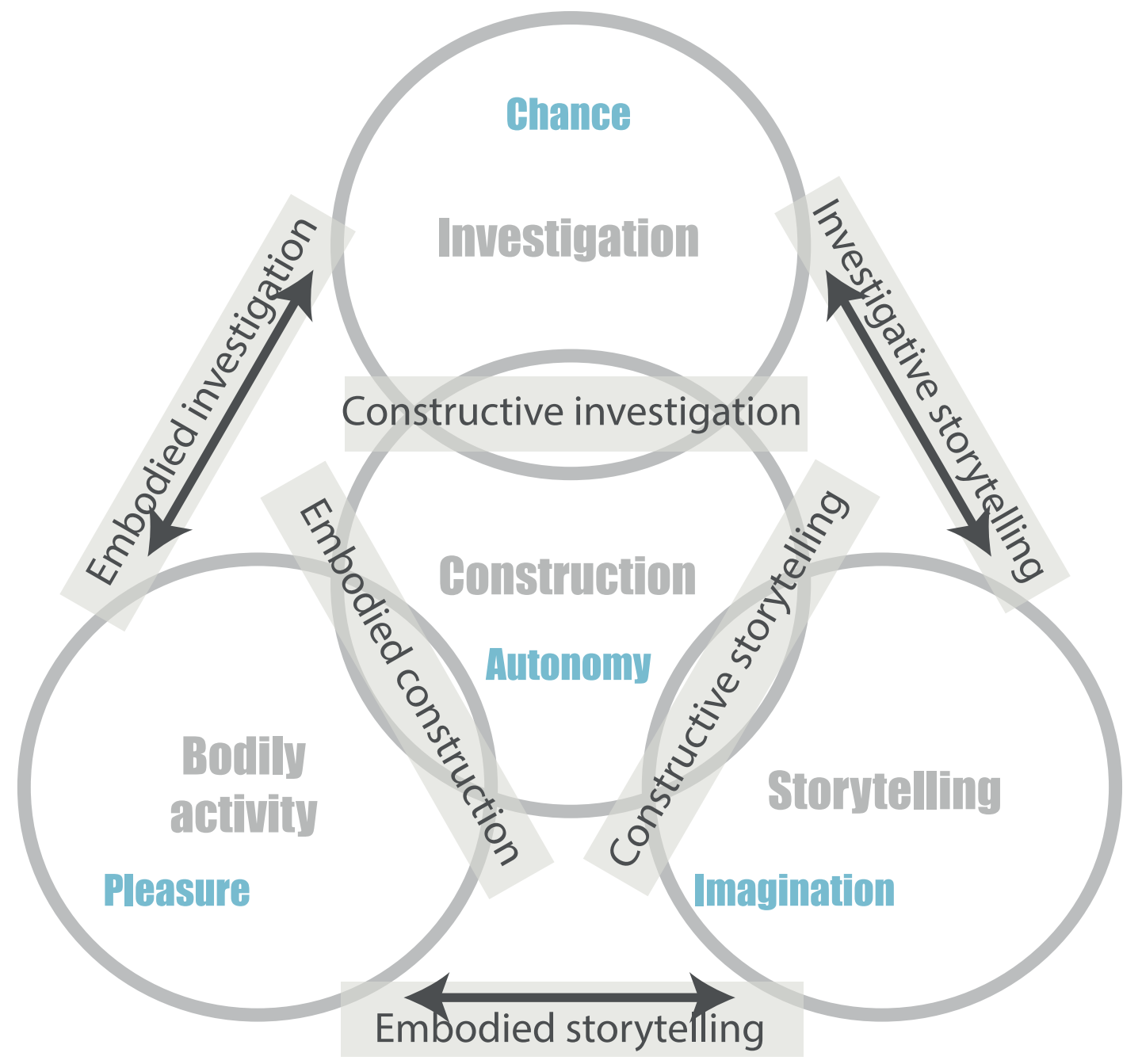

Figure 2. The core activities of the Play Blueprint combined into six basic play forms with the motivational drivers relating to each of the activities (e.g. imagination as a driver for storytelling). (Note: The four circles/activities stem from the Play blueprint by Legaard (2018), but has been rearranged and the six derived categories has been added by the author).

While I do not claim that these combinations into the six different play forms is the best or most accurate representation of play experiences, they do provide a useful platform for further exploration of the relation between play experiences and aesthetics of a designed artifact, i.e. a foundation for exploring the central question of this study: What is the link between aesthetic affordances and play experiences?" 


\section{Examining relations between aesthetics and play forms}

Kudrowitz and Wallace (2010: 4) describe play as a 'free movement with given affordances', paralleling affordances with what Salen and Zimmerman (2004: 304) describes as the 'rigid structures' of a game. Following from that, the affordances define the structure of the play experience, and the design of the play artifacts thus define the framing of the play activity, hereby nudging the person participating towards specific behaviors.

In order to explore how the designed affordances - in terms of the design aesthetics - relate to the resulting play experience, a study with thirty design students from the 'Design for play' master's programme at Design School Kolding was conducted. This particular empirical study was chosen in order to investigate the relations between aesthetics and the different forms of play experiences.

The overall aim of the study was to identify correlations between aesthetic expression and the six different play forms, in order to aid designers to understand and design for particular play experiences.

The students were asked to bring pictures of play situations and the artifacts that enabled them. This led to a set of approximately thirty play-related artifacts. The students were then divided into smaller groups, each given the task of analyzing the artifacts in relation to aesthetics, aiming to extract patterns of how the aesthetics related to the motive drivers of the activity types. The results from this exercise were presented and discussed in plenum, showing a notable relation between the aesthetic attributes of the different artifacts and which led to development of the model in figure 4.

The identified aesthetic attributes ranged between abstract/simple forms (e.g. bricks for construction) and more characteristic/representational forms (e.g. dolls or action figures). Some objects were considered to be 'in-between', having an ambiguous expression from which a personality and/or narrative could be interpreted.

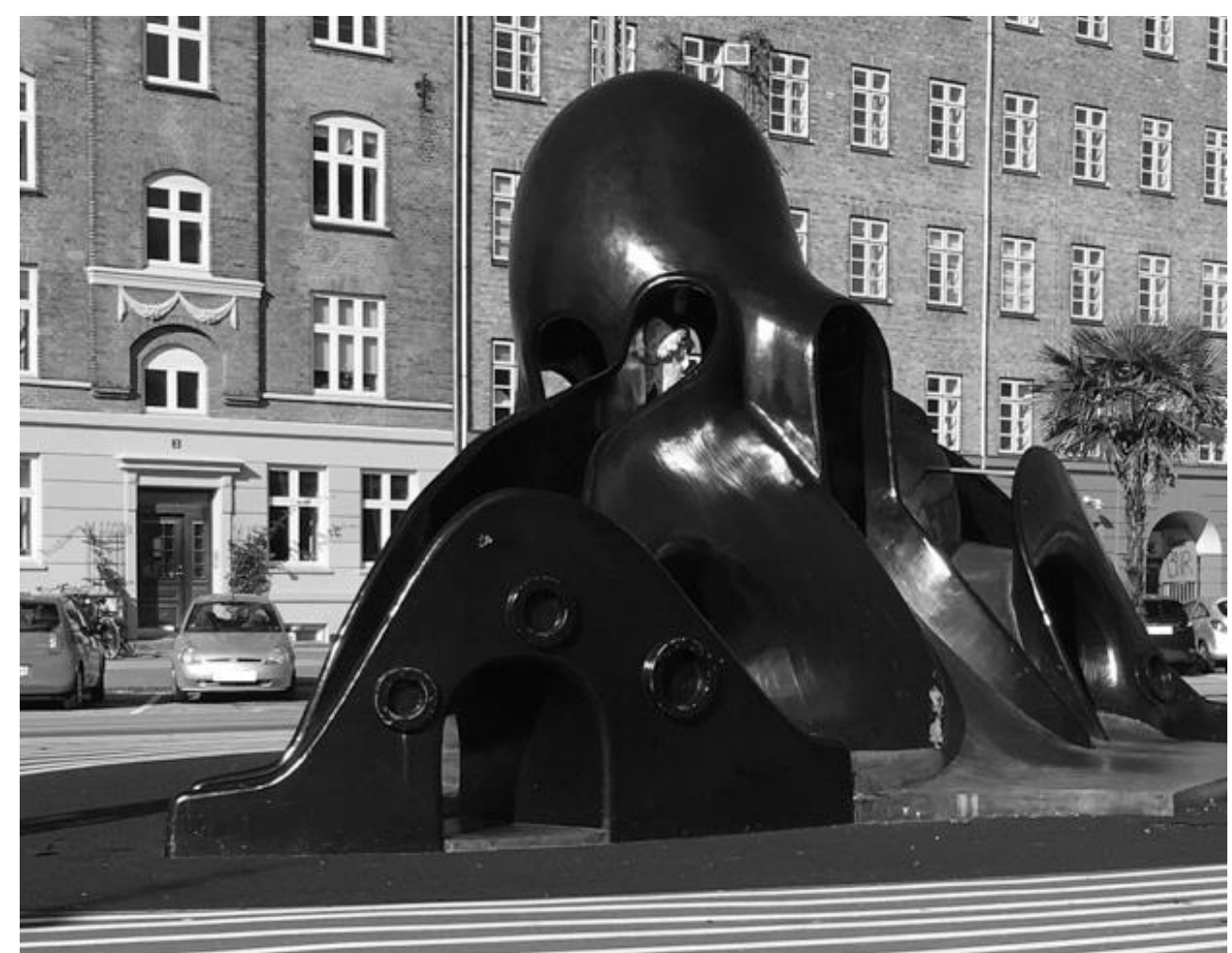

Figure 3. Play installation in Copenhagen. The design aesthetics sparks imagination without defining if it is a squid, a melting Darth Vader, a space ship or something else entirely. It is an interesting example of ambiguity in design aesthetics. (Photo by author) 


\subsection{Result}

Through the study we developed a scale ranging from simplistic forms to expressive/representational forms, within which the six different play forms were placed. As illustrated in figure 4 below, the study also identified a relation between play forms and how free the person playing is to alter/redefine the play framing. In very free play activities, the persons playing have to define the play space, whereas it is given in play activities with representational objects, for example a king and his castle.

The role of the artifact is, beyond its primary use, to mediate a certain state of being, either by supporting or disrupting the context and ambience of the experience. Folkmann (2013:26) notes that he regards aesthetics as "a central entry point for understanding how design mediates and conditions experience and our basic access to experience. Sensually, conceptually and contextually, design structures our experience".

When the aesthetics of the toy prescribe the play context (for instance the design of a castle) the person(s) playing will be focused on the experience of storytelling within that setting, possibly creating new connections when a dinosaur for instance tries to attack the castle. Objects that are more abstract or simple in its form (e.g. LEGO bricks) requires/allows the user to construct and develop the context for the storytelling themselves, in the attempts to match meta-reality and reality (object). The aesthetics are in this case more related to the interaction (designed for the function of construction) rather than the story, although the play experience can be enhanced when in combination with story-focused elements such as a window or a spear that can set the stage for constructive storytelling.

The developed scale in relation to the play forms are shown in figure 4 below.

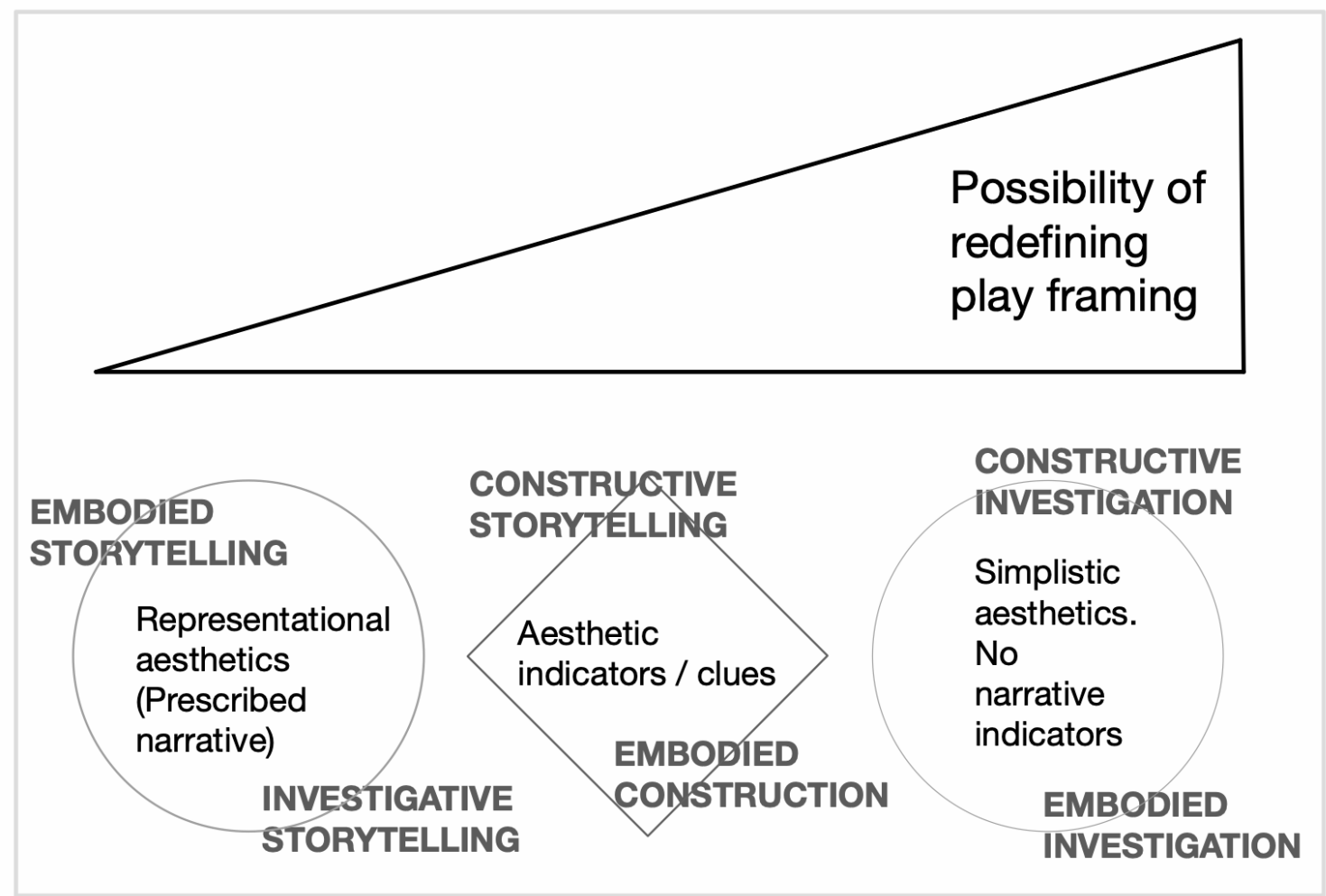

Figure 4. Correlation between play forms and aesthetic expression.

The illustration depicts three basic play states, these being (from right to left): The explorative/investigative state, the constructive state, and the narrative state. Where both the explorative state and the narrative state can exist on their own, the constructive state depends on the two others, needing both the freedom of exploration (supporting the autonomy of the 
activity) and the imagined narrative (adding something to direct the construction process towards). This indicates that there is a natural progression going from investigation through construction to storytelling, but not (necessarily) the opposite.

The transformation of a play experience often develops from the randomness in e.g. constructive investigation to the point where the one playing finds something that triggers constructive storytelling (something that links to a specific imaginary space, e.g. a window in the pile of LEGO that start the creation of a house), and further to developing narratives around the constructed play artifacts.

Objects for 'constructive investigation' (e.g. building blocks) also have similar form expression and scale that indicate that they can be combined in order to create something, i.e. there is a relational congruence between the objects.

\section{Designing for motivational drivers}

As noted in figure 2, the six play forms each have a set of two main drivers relating to the activities they build on, meaning that for instance 'Investigative storytelling' will have chance and imagination as main drivers. Examples of products that typically relate to this play form could be dolls or other toys that are designed with certain characteristics or personality, that allow them to be characters in a story (building on imagination as driver). The other motivational driver - chance - can come from interactions with other players, from items that are added while playing, or from reactions or features in the play artifact itself (for instance a doll that speaks or cries).

When children play with dolls we often see them investigating what that character would do in a certain situation, engaging with other children in imaginative situations.

This is an investigation of an existing situation mediated through the world that the toys offer (e.g. afforded by a certain type of dolls, a playhouse or other significant tokens of the type of world). As mediators of play experiences that link to storytelling, products need to be representative of the meta-reality of the play form, i.e. the physical manifestation of the play reality. If we compare this to constructive storytelling, the latter is signified by the buildup of the story-world as part of the experience. So that experience is driven by the autonomy of creating, with the imagination as the second driver, directing the building process towards the imaginary world that the one playing intends to create.

A third play form, constructive investigation, is signified by the trial and error approach to creation, incorporating chance ("what happens if I add this brick here?") and autonomy as drivers. If we for instance consider LEGO in relation to the play forms, they shift between the three play forms described here (CI, CS and IS). In one experience of building with LEGO, you can rapidly go through all three play forms, for instance starting in $\mathrm{CI}$ - just building to see what 'happens' when you put things together. The standard LEGO bricks are designed as simplistic but related objects with visual and proportional congruence, that also has a functional connectivity, hereby eliciting the 'constructive investigation' play form. At some point you may start to build towards a certain imaginary space (moving into CS), e.g. building a house, in which the randomness is minimized and the decisions are much more deliberate, aiming to remove the gap between the imagined world and the physicality of the bricks. Thirdly, when the physical manifestation is close 'enough' to the envisioned play world, you go into IS, starting to investigate this new world through the characters (in the case of LEGO this is where the minifigures for example come into play). LEGO play experiences tend to rapidly switch between CS and IS, i.e. between re-constructing and roleplaying. In the aesthetics of the bricks and figures, these play forms are supported by the diversity of the LEGO system, ranging from non-expressive objects affording connectivity (the bricks) to 
depictive elements (e.g. a window) that directs the imagination towards certain outcomes, and the instantly playable characters in the minifigures.

Besides the inherent motivational drivers described above, there can also be transitional drivers that are important for the transition from one play state to another.

A key driver in the process when going from 'constructive storytelling' to 'investigative storytelling' is the experience of cognitive dissonance. We know from cognitive dissonance theory (Festinger, 1957) that users may experience cognitive dissonance or psychological tension if their pre-acceptance playfulness perceptions are not confirmed in actual use. As we see with children aiming to match the framing of the play situation to the intended experience, users may try to reduce this dissonance either by modifying the physical object or framing, or by modifying their perceptions to be more consistent with reality. This is not only true for children - also adults who engage in constructive play often does so by trying to fit the play 'reality' (as expressed through the play objects) into the meta-reality, modifying physical objects to align with the meta-reality. (and vice versa - also adapting the perceived metareality to the physical objects).

This was also evident in a study by Legaard (2018) where adult participants created a row of domino-bricks combined with other things such as balls and pendula, to make a fun way to enhance the impression of the domino setup. One of the groups had included a little toy car which when pushed by a domino brick would run down a slope to make a jump, hereby pushing over the next domino brick. But they had also build a garage where more of the toy cars were put because, as they explained: "If the first driver doing this extremely dangerous stunt did not survive, a replacement driver would need to be ready".

So instead of considering the toy cars as just a functional mechanism bringing the motion of the domino setup to the next point in a more fun way, they saw it as a meta reality with a brave little driver, who had been given the task of doing this stunt.

This tension in the cognitive dissonance is both the challenge and opportunity for ambiguous designs, in that they require an acceptance as something that offers an interpreted but only partly prescribed meta-reality, giving both freedom of interpretation and requirement of adaptation to the play experience.

\section{Playfulness in non-play objects}

Designing artifacts with aesthetics that relate to play can, as mentioned above, both elicit play experiences and act as a playful addition to non-play experiences. For the latter, a playful surplus of meaning can have the purpose of increasing the experience of engagement with that object. Take as an example the 'form follows fiction' product line by Alessi which is directed towards storytelling, using imagination as a driver. This is evident in, for instance, the 'magic bunny' which is a toothpick holder shaped like a bunny in a hat.

But when it is not used within/for a play activity as such, it does not combine two drivers. It is not something that for example encourages you to investigate the storytelling (unless you use the artifact to play around with as a bunny on the dining table - but again, that would be playing). So, there is an indication that objects that only address one of the motivational drivers can be experienced as playful (but without the immersion into a play experience), whereas objects that address two of the motivational drivers typically lead to play experiences. But, as mentioned earlier in the paper, we can only design with an intention by proposing a certain usage, and then it is up to the person having the experience whether it becomes a play experience or not.

Experiences that build on construction typically requires a higher degree of immersion, in that there is a need to be engaged in the construction process, whereas play that builds on storytelling can be much more immediate, switching rapidly between the meta-reality and 
reality. The storytelling of the meta-reality can instantly be decoded, whereas construction requires interaction over time.

A quick fix for playfulness in products is for that reason often to add character to an object. For instance, the 'Dédé' doorstop designed for Alessi by Philippe Starck is designed with an aesthetics expression that builds on imagination designed as a man-like figure who is sitting (or actually waiting - in the words of Philippe Starck (Starck, 2020)). The founder of Alessi Alberto Alessi - is quoted for saying that "a true design work must move people, convey emotions, bring back memories, surprise, and go against common thinking." (Alessi, 2020). In this quote we can identify some of the important components of a play experience, for instance chance (surprise), disruption (going against common thinking) and bringing back memories, which links to imagination. So, the playful qualities that are evident in much of the design work by Alessi is an inherent part of their belief of what good design should offer. Sicart (2014: 20) writes (about particular user interface designs) that they "are driven by a desire to signal that the machine we are interacting with is not a serious computer but something else - something quirky and with personality that will not reject the form of expression through it but will actually encourage creativity. It is often this quirkiness and personality that gives an object an expression perceived as personality.

Some objects have an interaction which can be linked to playfulness. The previously mentioned 'magic bunny' toothpick holder by Alessi incorporates an element of embodied investigation, making the usage/interaction playful. The way that the toothpicks appear and gradually spreads out when the bunny is lifted adds an element of pleasurable surprise to the interaction. In designing playful interactions, there is often this possible link to embodied investigation (infusing the experienced interaction with elements of pleasure and surprise). A well-known Bang and Olufsen product - the Beosound 3000 - has a similar (albeit more subtle) form of playful features, relating to embodied investigation by the way the glass frames slide to the sides when you position your hand close to (but not touching) the CD player. The design of the product is simplistic with no narrative indicators. The link to embodied investigation comes from the interaction where the artifact response to a bodily movement. In this case there is furthermore an element of surprise, linking it directly to 'chance' as motivational driver. Designing for playfulness rather than 'play' means that the functional purpose must be the main feature, but the element of playfulness can add a positive feeling to the experience, without the immersion into a play activity. If you for instance only lift the bunny when grabbing a tooth pick and only make the Beosound 3000 slide open when you want to put in a $\mathrm{CD}$, you can have the sensation of playfulness without the immersion into a play experience.

\section{Conclusion}

The paper described aesthetics in relation to experiences, and more specifically how certain principles for the design of form and aesthetics can link to play and playful experiences, establishing a link to six identified play forms with different motivational drivers. The contribution of this paper is both the new classification of play in six play forms and the scale indicating aesthetic principles for play(ful) design that relates to the play forms as described in figure 4. Understanding the six play forms we can design for, and how they may be mediated through a designed artifact using aesthetic affordances, can aid designers to develop more engaging play experiences, and to utilize playful drivers in non-play experiences. 


\section{Future research / implications of the presented work}

The study presented in this paper is intended to be subject for further exploration, in order to gain deeper knowledge about and verify the described connections between the play forms, motivational drivers and aesthetic principles.

As described in the paper, the classification of play forms in relation to aesthetics is not only considered useful for designers of toys (as a way to create toys that link to specific play forms and the interchangeability between them) but is also something that can be useful in relation to e.g. learning through play (different play forms support different ways of learning and learning outcomes, e.g. cognitive skills, social skills and motor skills) or as an approach to incorporate a suited form of playfulness in e.g. a work setting.

The study intends to be useful as an inspirational resource, providing principles for how to for design for specific forms of playfulness, which for instance could be used to increase the creativity within a company culture through the design of playful interiors. Likewise, the study could inspire creative processes by aligning them to play forms; generating new concepts through constructive investigation, developing the concepts through constructive storytelling and exploring what users will experience through 'embodied storytelling'. It is the overall ambition with the research presented in the paper, that it can aid to developing more fun, more engaging and more meaningful experiences for both children and adults.

\section{Acknowledgement}

The author would like to thank all the students who participated in the study, as well as my colleagues in the Lab for Play and Design at Design School Kolding - I greatly appreciate our many interesting discussions of what play is and what play can do.

\section{References}

Alessi (2020). Retrieved 05.02.2020 from http://www.alessi.com/design/en/dreamfactory/about-us.

Bailey, J. and Story, C. (2018). Aestheticising Change: simulations of progress. In Proceedings of DRS2018: Catalyst, Limerick 25th - 28th June 2018.

Blythe, M. And Hassenzahl, M. (2003). The semantics of fun: Differentiating enjoyable experiences. In M. Blythe, C. Overbeeke, A. F. Monk, \&amp; P. C. Wright (Eds.), Funology: From Usability to Enjoyment. Dordrecht: Kluwer, 2003, pp. 91-100.

Caru, A. and Cova, B. (2006). How to facilitate immersion in a consumption experience: Appropriation operations and service elements. In Journal of Consumer Behaviour 5. pp. 4-14

Csikszentmihalyi, M. (1990). Flow: The Psychology of Optimal Experience 1st edn., Harper Perennial Modern Classics.

de Valk, L., Bekker, T., and Eggen, B. (2015). Designing for Social Interaction in OpenEnded Play Environments. International Journal of Design.

Festinger, L. (1957). A theory of cognitive dissonance, Evanston, IL: Row \& Peterson.

Gordon, G. (2009). What is Play? In Search of a Definition. From Children to Red Hatters:

Diverse Images and Issues of Play, Play \& Culture Studies, Vol. 8, edited by David Kuschner, 1-13.

Folkmann, M., N. (2013). The Aesthetics of Imagination in Design. Cambridge, MA: MIT Press. 
Hassenzahl, M. (2010). Experience Design: Technology for All the Right Reasons, 1-95. In Morgan and Claypool 3 (1).

Jensen, J. L., \& Coxon, I. R. (2013). [Innovation from] a shared journey between designers and users: Explicating the XbD process. 3rd INT. CONF. ON INTEGRATION OF DESIGN, ENGINEERING \& MANAGEMENT FOR INNOVATION, Porto.

Jensen, J. L. (2014). Designing for profound experiences. Design Issues; 30(3): 39-52.

Kudrowitz, B., \& Wallace, D. (2010). The play pyramid: A play classification and ideation tool for toy design. International Journal of Arts and Technology, 3(1), 36-56.

Ladwein R. (2003). Les me' thodes de l'appropriation de l'expe' rience de consommation. In Socie te', ConsommationetConsommateurs, Re' myE, Garubuau-Moussaoui I, Desjeux D, Filser M, Garubuau- Moussaoui I (eds). L'Harmattan: Paris, France; 83-95.

Legaard, J. (2018). The road to happiness is paved with playful intentions. In Proceedings of DRS2018: Catalyst, Limerick 25th - 28th June 2018.

Norman, D., \& Verganti, R. (2013). Incremental and radical innovation:Design research vs technology and meaning change. DesignIssues, 30, 78-96.

Overbeeke, K., Djajadiningrat, D., Hummels, S., Wensveen, S., and Frens, J., (2003). "Let's make things engaging," in Funology: From Usability to Enjoyment, Blythe, M., Overbeeke, K., Monk, A., and Wright, P., Eds., pp. 7-18, Kluwer Academic Publishers, Dordrecht, The Netherlands.

Peter, B. (2013). Form follows fun: Modernism and modernity in British Pleasrure architecture 1925-1940. Routledge, Oxon.

Pine, J. B. and Gilmore, J. (1998). "Welcome to the Experience Economy," Harvard Business Review.

Proyer, R. T. (2013). The Well-Being of Playful Adults: Adult Playfulness, Subjective WellBeing, Physical Well-Being, and the Pursuit of Enjoyable Activities." European Journal of Humour Research 1:84-98.

Salen, K. and Eric, Z. (2004) Rules of Play: Game Design Fundamentals. Cambridge, MA: MIT Press.

Sicart, M. (2014). Play Matters. Cambridge, Massachussets: The MIT Press.

Sullivan, L. H. (1896). The tall office building artistically considered. Getty Research Institute.

Starck (2020). Retrieved 22.01.2020 from: http://www.starck.com/dede-p2078.

Verbeek, P. (2011). Moralizing Technology: Understanding And Designing The Morality Of Things, University of Chicago Press.

Webster, J., L.K. Trevino, L. Ryan (1993). "The Dimensionality and Correlates of Flow in Human Computer Interactions," Computers in Human Behavior, 9(4), Winter 1993 411- 426. 